\title{
Consumer Evaluation of Brand Alliance Under Distraction: An Abstract
}

\author{
Kevin E. Voss and Ying Ying Li
}

\begin{abstract}
A brand alliance involves "two or more brand names \{that $\}$ are featured simultaneously in a product context" (Rao et al. 1999, p. 259). Previous research suggests that a consumer's evaluation of a previously unknown focal brand is more positive when that brand is partnered with a known product brand ally than with no ally (e.g., Rao et al. 1999; Washburn et al. 2004; Voss and Gammoh 2004; Gammoh et al. 2010). However, there is some reason to suggest that brand alliance cues may be a relatively weak communication device. For example, Desai and Keller (2002) found that for slot-filler extensions, brands did better over time without an ally. In this research, we examine the effect of mental distraction on consumer evaluations of the focal brand in a brand alliance.

We contribute to the brand alliance literature by exploring how distraction affects customer evaluations of the focal brand in brand alliances. In study one, we replicate the brand alliance effect from previous research by finding that attitude toward the focal brand is significantly higher with the ally than without an ally. However, under both a cognitive load manipulation and a visual load manipulation, attitudes toward the brand ratings for the focal brand were significantly lower than the condition with the ally alone but no mental load. In study two, the use of a sex appeal disturbed recognition of the brand ally. Both males and females reported lower levels of recognition of the brand ally, but this difference was only significant for females viewing a bikini ad. Thus, participant's evaluation of the focal brand was lower under distraction.

The results of the current research reveal that brand alliance cues seem to be significantly less persuasive under distraction than when they are focused on the persuasive communication. When the ad contains cues that compete for attention with brand ally cue, the persuasive impact of the brand ally cue seems to decrease. It should be noted that in these two studies, we do not have process mediators to indicate why the evaluations decrease. This is a needed addition for future research.
\end{abstract}

\footnotetext{
K. E. Voss $(\bowtie) \cdot$ Y. Y. Li

Oklahoma State University, Stillwater, OK, USA

e-mail: kevin.voss@okstate.edu; yingying.li@okstate.edu
} 